\title{
LOS PRINCIPIOS RECTORES, NORMAS Y POLIITICAS VENEZOLANAS DE PROTECCIÓN DEL AMBIENTE EN CONTRASTE CON EL DECRETO DE CREACIÓN DEL ARCO MINERO DEL ORINOCO ${ }^{1}$
}

\author{
Juan Domingo Alfonzo Paradisi ${ }^{2}$ \\ Universidad Católica Andrés Bello (UCAB) \\ Artigo recebido em: 18/11/2019. \\ Artigo aceito em: 19/11/2019.
}

\section{Resumo}

El presente trabajo tiene por objeto reseñar en primer lugar, los principios rectores, así como las normas de protección del ambiente en Venezuela tanto de rango constitucional, legal y sublegal y fundamentalmente, en segundo lugar, destacar el contraste, así como la violación a dichos principios y normas en materia ambiental por el Decreto 2.248/2016 dictado por el Presidente de la República mediante el cual se crea "La Zona de Desarrollo
Estratégico Nacional Arco Minero del Orinoco (AMO)" afectando una extensión territorial de $111.843,70$ $\mathrm{km}^{2}$. La investigación se desarrolló con el método de razonamiento deductivo y la téncia de investigación bibliográfica y articulos científicos, asi como la investigación de la legislación nacional.

Palavras-clave: Arco Minero del Orinoco; medio ambiente; Políticas venezolanas; principios.

1 Trabajo presentado en fecha 20 septiembre 2018 en el V Congreso Internacional de Derecho Ambiental y Desarrollo Sustentable en la Escola Superior de Derecho Dom Helder Camara en Belo Horizonte, Brasil.

2 Maestría en Estudios Superiores en Administración Pública Instituto Nacional de Administración Pública por el Instituto Nacional de Administración Pública (INA), en Espańa. Abogado Especialista en Derecho Administrativo por la Universidad Católica Andrés Bello (UCAB). Profesor de Derecho Administrativo (Pre y Postgrado) en la Universidad Central de Venezuela (UCV) y en la UCAB. Profesor de Postgrado en Derecho Administrativo en la UCAB. Profesor de Pregrado en Derecho Administrativo I en la UCV. E-mail: jalfonzo@tpa.com.ve 


\section{THE GUIDING PRINCIPLES, VENEZUELAN RULES AND POLICIES OF PROTECTION OF THE ENVIRONMENT IN CONTRAST WITH THE CREATION OF THE DECREE ABOUT ORINOCO MINING ARCH}

\section{Abstract}

The purpose of this paper is to review, in the first place, the guiding principles, as well as the norms of environmental protection in Venezuela of both constitutional, legal and sub-legal rank and, fundamentally, secondly, to highlight the contrast, as well as the violation of said principles and norms in environmental matter by Decree 2.248 / 2016 issued by the President of the Republic by means of which "The National Strategic Mining Area of the Orinoco Arc (AMO)" is created, affecting a territorial extension of $111,843.70 \mathrm{~km}^{2}$. The research was carried out with the deductive reasoning method and the literature research and scientific articles, as well as the investigation of national legislation.

Keywords: environment; principles; Orinoco Minining Arch; Venezuelan policies. 


\section{Introducción}

El presente trabajo tiene por objeto reseñar en primer lugar, los principios rectores, así como las normas de protección del ambiente en Venezuela tanto de rango constitucional, legal y sublegal y fundamentalmente, en segundo lugar, destacar el contraste, así como la violación a dichos principios y normas en materia ambiental por el Decreto 2.248 dictado por el Presidente de la República, publicado en la Gaceta Oficial n. 40.855 de fecha 24 de febrero de 2016, mediante el cual se crea "La Zona de Desarrollo Estratégico Nacional Arco Minero del Orinoco $(A M O)$ " afectando una extensión territorial de $111.843,70 \mathrm{~km}^{2}$.

A través de la presente investigación abordaremos los principios rectores en materia ambiental desarrollados por normas de rango constitucional y legal así como en convenios internacionales aprobados por Venezuela y principalmente destacaremos el no seguimiento y violación de varios de ellos por el Decreto de Creación del Arco Minero del Orinoco (AMO).

Lo ideal es que se alcance un desarrollo económico sustentable y que exista una armonía entre el desarrollo económico y el medio ambiente, así como la debida protección del ambiente y de los recursos naturales.

\section{Principios rectores constitucionales y normas legales en Derecho Ambiental venezolano}

Los principios rectores previstos en la Constitución Nacional y en las leyes ambientales rigen para los órganos del Poder Público y para el ejercicio de sus funciones jurídicas, así como también para la tutela y protección de los derechos humanos. Estos principios rectores que constituyen normas rectoras del derecho ambiental y que se precisan como principios que rigen los diferentes regímenes jurídicos aplicables a la conservación defensa y mejoramiento del ambiente. $\mathrm{Al}$ establecer la Constitución o las leyes determinados principios como normas rectoras las convierte mediante la técnica jurídica en fórmulas más o menos amplias en Derecho positivo e implicando así un punto de referencia para la interpretación y aplicación del derecho vigente formulado en normas-reglas (MEIER, 2011; 2003) Se puede diferenciar según ha señalado un sector de la doctrina (MEIER, 2011), en relación de la naturaleza jurídica de estos principios rectores algunos de carácter vinculante pero poco operativos que requieren una progresiva implementación por medio de política públicas (planes, programas, proyectos, medidas etc.); de los principios que pueden aplicarse de forma inmediata y por tanto de naturaleza operativa, mediante normas-reglas, es decir por medio de ejercicios de los derechos 
ambientales de las personas naturales jurídicas o por medio de ejercicio de las potestades y deberes de los organismos que integran la administración pública. Aquí de seguidas, seguimos al profesor Henrique Meier y la sistematización por él ofrecida en relación a los principios de derecho ambiental.

\subsection{Principios rectores vinculantes, pero poco operativos}

\subsubsection{Principio de desarrollo sustentable}

El artículo 299 de la Constitución venezolana establece dentro de los principios del régimen socio económico de la República Bolivariana de Venezuela: la protección del ambiente. De allí pues, la relación entre desarrollo económico y protección del ambiente se subsume en el concepto del "desarrollo" ecológicamente sustentable y sostenible y la sustentabilidad y su mantenimiento en el tiempo depende del grado de preservación de los bienes que conforman la base material ecológica de ese proceso: suelos, bosques, aguas, capa vegetal, especies vivas (MEIER, 2011). De allí pues, el daño irreversible a los recursos naturales compromete no solo el disfrute de una calidad de vida ambiental, sino que también pone en peligro las actividades productivas de la sociedad.

Lo importante en el caso venezolano de conformidad con el Plan de la Patria 2013-2019 publicado en Gaceta Oficial n. 6.118 extraordinaria de fecha 4 de diciembre 2013, el cual constituye un mecanismo de ordenación económica en Venezuela que ha pretendido tener carácter de Ley (MEIER, 2011). No obstante ello, dicho plan ha sido seguido por el gobierno en términos generales desde el punto de vista indicativo en sus politicas públicas estableciéndose en el mismo- en su gran objetivo histórico n. 3- el carácter de industria extractiva de la economía venezolana en referencia al petróleo, minería: oro, coltán entre otros.

Gran Objetivo Histórico n. 3

III. Convertir a Venezuela en un país potencia en lo social, lo económico y lo político dentro de la Gran Potencia Naciente de América Latina y el Caribe, que garanticen la conformación de una zona de paz en Nuestra América.

Así, se establece en el Plan de la Patria 2013-2019 en su Objetivo Nacional n. 3:

3.1. Consolidar el papel de Venezuela como Potencia Energética Mundial.

Objetivos Estratégicos y Generales

3.1.15.3. Duplicar las reservas minerales de bauxita, hierro, 
coltán (niobio y tantalita), níquel, roca fosfórica, feldespato y carbón, con la certificación de los yacimientos ubicados en el Escudo de Guayana, Cordillera de los Andes, Sistema Montañoso del Caribe y la Sierra de Perijá.

3.1.16.4. Conformar empresas mixtas para la explotación y procesamiento de bauxita, hierro, coltan (niobio y tantalia), niquel, roca fosfórica, feldespato y carbón; en las cuales la República tenga el control de sus decisiones y mantenga una participación mayoritaria (VENEZUELA, 2013, Subrayado nuestro).

Ahora bien, a pesar de la decisión del gobierno venezolano de determinar su industria como extractiva, ello no puede implicar un divorcio con la debida protección del ambiente y de los recursos naturales, así como de la sustentabilidad y sostenibilidad en el tiempo del proceso de desarrollo económico el cual debe ser económicamente sustentable y sostenible de acuerdo a los principios rectores en materia ambiental que prevé la Constitución vigente.

En relación con el vínculo entre desarrollo económico y protección del ambiente el Tribunal Constitucional español ha señalado lo siguiente:

El desarrollo económico es igualmente necesario para lograr la calidad de vida, por lo que la conclusión que se deduce del examen de los preceptos constitucionales lleva a la necesidad de compaginar en la forma en que cada caso decida el legislador competente, la protección de ambos bienes jurídicos constitucionales: el medio ambiente y el desarrollo económico. Si el Estado ha declarado la prioridad de determinadas actividades extractivas para la defensa de la economía nacional, hay que respetar esa prioridad...no puede considerarse como objetivo primordial y excluyente la explotación al máximo de los recursos naturales, el aumento de la producción a toda costa, sino que se ha de armonizar la utilización racional de estos recursos con la protección de la naturaleza, todo ello para el mayor desarrollo de la persona y para asegurar una mejor calidad de vida (ESPAÑA, 1982, subrayado nuestro).

Así las cosas, a pesar de que Venezuela a través del Plan de la Patria haya declarado la prioridad de determinadas industrias extractivas por ejemplo petróleo y minería, ello no obsta, ni impide armonizar la utilización racional de esos recursos con la protección de la naturaleza y de los recursos naturales para el mejor desarrollo de la persona y asegurar la calidad de vida. 
Así mismo, el artículo 50 de la Ley Orgánica del Ambiente en lo adelante "LOA" establece:

El aprovechamiento de los recursos naturales y de la diversidad biológica debe hacerse de manera que garantice su sustentabilidad".

Por tanto, la explotación y el desarrollo debe ser ecológicamente sustentable y preservan, como se ha dicho los bienes ambientales entre otros los bosques, las aguas, los recursos hídricos y la capa vegetal, evitando así la tala indiscriminada, la degradación y contaminación de las aguas, y permitiendo el uso de los recursos hídricos para garantizar la conservación de la vida y el desarrollo económico (VENEZUELA, 2006).

En este sentido el artículo 3 de la "LOA" define el aprovechamiento o utilización sustentable de los bienes ambientales como:

Proceso orientado a la utilización de los recursos naturales y demás elementos de los ecosistemas, de manera eficiente y socialmente útil, respetando la integridad funcional y la capacidad de carga de los mismos, en forma tal que la tasa de uso sea inferior a la capacidad de regeneración"; y de igual manera se define el artículo 3 de la "LOA" define como Desarrollo sustentable: Proceso de cambio continuo y equitativo para lograr el máximo bienestar social, mediante el cual se procura el desarrollo integral, con fundamento en medidas apropiadas para la conservación de los recursos naturales y el equilibrio ecológico, satisfaciendo las necesidades de las generaciones presentes sin comprometer las generaciones futuras (VENEZUELA, 2006).

Así pues, este principio de desarrollo sustentable para convertirse en un principio operativo requiere su traducción en normas-reglas, medios y técnicas jurídicas y normas procedimentales; programas y proyectos de desarrollo; procedimientos de control autorizatorio, evaluación ambiental y los estudios de impacto ambiental; la prohibición de actividades susceptible de dañar el ambiente de modo irreversible o irreparable; en definitiva el conjunto de técnicas derivadas de los principios de prevención, precaución, prudencia que se explicarán infra.

En cuanto a esta importante relación entre desarrollo económico y protección del ambiente el artículo 24 de la "LOA" establece:

La planificación del ambiente forma parte del proceso de desarrollo sustentable del país. Todos los planes, programas y proyectos 
de desarrollo económico y social, sean de carácter nacional, regional, estadal o municipal, deberán elaborarse o adecuarse, según proceda, en concordancia con las disposiciones contenidas en esta Ley y con las políticas, lineamientos, estrategias, planes y programas ambientales, establecidos por el ministerio con competencia en materia de ambiente (VENEZUELA, 2006).

Seguindo o caminho dos princípios ambientais, a seguir compreenderemos como o cidadão participa da proteção ambiental em Venezuela.

\subsubsection{Principio de Corresponsabilidad entre el Estado y la Sociedad en la Gestión de Bienes Ambientales y la Participación Ciudadana, la Conservación y Mejoramiento del Ambiente}

La Constitución de la República Bolivariana de Venezuela (CRBV) prevé el principio de corresponsabilidad en el artículo 326 estableciendo "El principio de la corresponsabilidad se ejerce en los ámbitos económico social, políticos, cultural, geográfico, ambiental y militar”.

Así mismo, en los artículos 127 y 128 se establece "la obligación del Estado de garantizar a los pueblos un ambiente sano, libre de contaminación”. El derecho-deber de cada generación de proteger y mantener el ambiente en beneficio de sí misma y del mundo futuro. La obligación del Estado de proteger el ambiente y la diversidad biológica, los procesos ecológicos, los parques nacionales, monumentos naturales y demás áreas de especial importancia ecológica, art. 127 CRBV (VENEZUELA, 1999).

De igual manera se establece como obligación fundamental del Estado, con la activa participación de la sociedad garantizar que la población se desenvuelva en un ambiente libre de contaminación, en donde le aire, el agua, los suelos, la capa de ozono, el clima, las costas y las especies vivas, sean especialmente protegidos de conformidad con la ley.

Por otra parte, la Constitución venezolana prevé el deber del Estado de establecer una política de ordenación del territorio atendiendo a las necesidades ecológicas, poblacionales, culturales, sociales, geográficas, económicas y políticas de acuerdo a las premisas de desarrollo sustentable. 


\subsection{Principios Operativos de Aplicación Inmediata en Virtud de Técnicas Jurídicas}

A diferencia de los principios anteriormente señalados, estos son de aplicación inmediata, por instrumento de las normas-reglas legales que contienen las diferentes técnicas o medios específicos creados a tales fines. La fuerza normativa de ellos no admite discusión.

\subsubsection{Principio de precaución}

Según el artículo 4.3 de la "LOA": "la falta de certeza científica no puede alegarse como excusa o razón suficiente para no adoptar medidas preventivas y eficaces en caso de actividades que puedan impactar negativamente el ambiente". (VENEZUELA, 2006)

El principio de precaución, cuya finalidad es la preservación del ambiente justifica cualquier medida preventiva, eficaz para impedir la realización de actividades capaces de degradar bienes ambientales.

Ha sido desarrollado por diversas leyes en Venezuela, entre otras, la ya citada Ley Orgánica del Ambiente (en lo adelante "LOA"), en sus artículos 4.3, 84 y 85, así como en el artículo 4 de la Ley de Biodiversidad. De igual manera el artículo 3.6 de le Ley de Bosques establece:

Art. 3 Las disposiciones de esta ley se aplican bajo los siguientes principios:

6. Precaución: la obligación de evitar o prevenir decisiones que impliquen riesgos o posibilidad de daños graves o irreparable a los bosques y al patrimonio forestal, no puede evadirse invocando la falta de certeza científica (VENEZUELA, 2006, Subrayado nuestro).

Así mismo, el principio de precaución es previsto en el Convenio de Río de 1992 aprobado por Venezuela:

PRINCIPIO 15: Con el fin de proteger el medio ambiente, los

Estados deberán aplicar ampliamente el criterio de precaución conforme a sus capacidades. Cuando haya peligro de daño grave o irreversible, la falta de certeza científica absoluta no deberá utilizarse como razón para postergar la adopción de medidas eficaces en función de los costos para impedir la degradación del medio ambiente. 
Mención de la Opinión Consultiva de la Corte Interamericana de Derechos Humanos (OC23). Según la OC23 de la Corte Interamericana de DDHH, párrafo 175:

"el principio de precaución, en materia ambiental, se refiere a las medidas que se deben adoptar en casos donde no existe certeza científica sobre el impacto que pueda tener una actividad en el medio ambiente" (Subrayado nuestro).

El Decreto con Rango, Valor y Fuerza de Ley de Pesca y Agricultura (LDPA, GO n. 5.877 del 14 de marzo de 2008) también contiene dicho principio:

"El Estado deberá aplicar ampliamente el criterio de precaución en el ordenamiento y la explotación de los recursos hidrobiológicos con el fin de conservarlos y de proteger al medio acuático. Cuando haya peligro de daño graveo irreversible, la falta de certeza absoluta o información científica no será motivo para aplazar o dejar de adoptar las medidas a conservar el ambiente, los organismos que son objeto de la pesca y acuicultura, los asociados o dependientes y aquellos que no son objeto de la pesca” (artículo 29) (ONU, 1992, Subrayado nuestro).

Así señala el profesor Meier, la precaución ambiental se traduce en el adagio jurídico "in dubio pro natura", en caso de duda debe favorecerse el interés público ambiental, la protección de los bienes ambientales. Tal adagio es una interpretación y aplicación analógica del principio de Derecho Penal "In dubio pro reo" (MEIER, 2011, p. 62).

Pareciera que la precaución es previa a la prevención, pues esta opera una vez que el principio de precaución efectúa su función. Los pasos o fases para la aplicación de ambos principios en el control de actividades susceptible de degradar el ambiente son los siguientes:

-Primero, se debe evaluar e identificar el riesgo potencial de la actividad, los efectos potencialmente negativos que podría generar esa actividad. Esta primera fase ha de llevarse a cabo sobre la base de datos científicos y técnicos fiables y un razonamiento que pondere las probabilidades de la gravedad del riesgo para la salud humana y el ambiente tomando en cuenta: dańos posibles, reversibilidad, efectos en el tiempo.

-Segundo, de esa evaluación inicial surgen dos posibilidades: a) Que la falta de certeza científica impida la posibilidad de prevenir los riesgos del dańo y, en consecuencia, se aplique el 
principio de precaución prohibiendo la realización de la actividad susceptible de degradar el ambiente.

b) Que efectivamente con los conocimientos científicos disponibles los riesgos potenciales puedan ser objeto de control. En este supuesto, se aplicará el principio de prevención y la técnica del estudio del impacto ambiental con el objeto ¿de establecer el tipo de riesgo, los daños potenciales y las medidas para mitigar, corregir y restaurar el daño ambiental.

En suma, la prevención y la precaución legitiman dos tipos de prohibiciones y actividades para garantizar la protección ambiental señalada por el profesor Meier:

a) Prohibición normativa absoluta: Cuando se tiene certeza científica respecto al daño ambiental grave e irreversible que ocasionan una actividad susceptible de degradar el ambiente, la prohibición debe expresarse legalmente y fundarse en la presunción jure de jure (que no admite prueba en contrario) es decir un daño cierto.

b) Prohibición administrativa: Cuando se carece de certeza científica acerca del probable impacto degradante de una actividad, es decir cuando se presume el riesgo de un daño probable, la autoridad administrativa competente debe adoptar la medida preventiva acorde con la situación en pocas palabras, no autorizar la actividad (MEIER, 2011, p. 65, Subrayado nuestro).

\subsubsection{Principio Precautorio o de Prevención}

Se prevé desde la Constitución Venezolana de 1999 como principio fundamental el principio de prevención, como "principio maestro del Derecho Ambiental" y como estrategia fundamental y prioritaria, estableciéndose su técnica operativa en la propia norma constitucional, artículo 129 de la Constitución de la República Bolivariana de Venezuela, como lo constituye, la obligación general de presentar el "Estudio de Impacto Ambiental" en toda actividad susceptible de generar daños a los ecosistemas.

Esta exigibilidad del estudio de impacto ambiental ha sido igualmente prevista y desarrollada por normas de rango legal y sublegal como lo son la "LOA" (art. 84 y 85), en la Ley de Biodiversidad, en adelante "LDB" (art. 4) y de manera especial ha sido desarrollada por el Decreto 1.257 publicado en la Gaceta Oficial 35.946 del 25 de abril de 1986. 
En Venezuela se establece en su legislación un sistema procedimental autorizatorio que engloba las garantías necesarias para asegurar la mejor localización de las actividades humanas en el territorio. "Estos procedimientos autorizatorios se agrupan en aquellos que tienen que ver con la ocupación del territorio, con los estudios de impacto ambiental, con el aprovechamiento de los recursos naturales y con el control de las actividades susceptibles de degradar el ambiente"3.

La doctrina ha señalado que de las tres grandes estrategias para alcanzar metas razonables en la conservación, defensa y mejoramiento del ambiente: La prevención, la represión, la reparación y la restauración del daño ambiental y ecológico, la primera supera en jerarquía axiológica y practica a la segunda y a la tercera y que la represión y la reparación son estrategias definitivamente complementarias.

Así se ha sostenido que es preferible prevenir la degradación, contaminación y daños a los mismos que remediar posteriormente tales perjuicios, ya que en muchos casos la restauración es científicamente imposible (daños irreversibles). Así las cosas, esta prioridad axiológica la reconoce el artículo 4.2 de la "LOA".

Artículo 4.2: "La gestión del ambiente comprende:

Prevención: Medida que prevalecerá sobre cualquier otro criterio en la gestión del ambiente" (VENEZUELA, 2006, Resaltado nuestro).

Así mismo, en la "LOA" publicada en la Gaceta Oficial n. 5.833 Extraordinario del 22 de diciembre de 2006, en sus diversos artículos se establecen normas que prevén el principio de prevención, dentro de las cuales podemos mencionar:

Artículo 40: El Ejecutivo Nacional, a través del ministerio con competencia en materia ambiental, reglamentará los mecanismos para hacer efectivo el ejercicio legítimo del derecho a la participación ciudadana en la formulación, adopción, ejecución y control de las políticas, planes, proyectos y otras medidas dirigidas a la conservación del ambiente.

Artículo 77: El Estado, a través de la Autoridad Nacional Ambiental, ejercerá el control ambiental sobre las actividades y sus efectos capaces de degradar el ambiente, sin menoscabo de las competencias de los estados, municipios, pueblos y comunidades indígenas, en aquellas materias ambientales expresamente asignadas por la Constitución y las

3 Blanco Uribe, Alberto: "La Tutela Ambiental como Derecho- Deber del Constituyente. Base Constitucional y Principios Rectores del Derecho Ambiental”. Revista de Derecho Constitucional n. 6 . Editorial Sherwood, Caracas, 2002. p. 52 
leyes, garantizando así la gestión del ambiente y el desarrollo sustentable. El artículo 80 establece una serie de actividades susceptibles de degradar el ambiente.

\section{Artículo 80:}

Se consideran actividades capaces de degradar el ambiente:

1. Las que directa o indirectamente contaminen o deterioren la atmósfera, agua, fondos marinos, suelo y subsuelo o incidan desfavorablemente sobre las comunidades biológicas, vegetales y animales.

2. Las que aceleren los procesos erosivos y/o incentiven la generación de movimientos morfodinámicos, tales como derrumbes, movimientos de tierra, cárcavas, entre otros.

3. Las que produzcan alteraciones nocivas del flujo natural de las aguas.

4. Las que generen sedimentación en los cursos y depósitos de agua.

20. Cualesquiera otras que puedan dańar el ambiente o incidir negativamente sobre las comunidades biológicas, la salud humana y el bienestar colectivo.

Artículo 83: El Estado podrá permitir la realización de actividades capaces de degradar el ambiente, siempre y cuando su uso sea conforme a los planes de ordenación del territorio, sus efectos sean tolerables, generen beneficios socioeconómicos y se cumplan las garantías, procedimientos y normas. En el instrumento de control previo se establecerán las condiciones, limitaciones y restricciones que sean pertinentes (VENEZUELA, 2006, Subrayado nuestro).

Se ha sostenido el Principio del Daño Permisible como un principio rector, pero según otro sector de la doctrina, en realidad es una consecuencia del principio de prevención ${ }^{4}$, y de lo que se trata, es de permitir o tolerar algunos dańos en tanto y en cuanto sean: conformes a los planes de ordenación de territorio, sean tolerables, generen beneficios socioeconómicos y se cumplan con las garantías procedimentales y del debido proceso tal y como lo prevé el artículo 83 de la Ley Orgánica del Ambiente.

Artículo 84: La evaluación de impacto ambiental está destinada a: 1-Predecir, analizar e interpretar los efectos ambientales potenciales de una propuesta en sus distintas fases.

4 Blanco Uribe, Alberto: La Reparación Ambiental en Venezuela. En Responsabilidad por dańos al Medio Ambiente. Universidad Externado de Colombia, Bogotá. 1999. 
2-Verificar el cumplimiento de las disposiciones ambientales.

3-Proponer las correspondientes medidas preventivas, mitigantes y correctivas a que hubiere lugar.

4-Verificar si las predicciones de los impactos ambientales son válidas y las medidas efectivas para contrarrestar los daños.

Artículo 85: El estudio de impacto ambiental y sociocultural constituye uno de los instrumentos que sustenta las decisiones ambientales, comprendiendo distintos niveles de análisis, de acuerdo con el tipo de acción de desarrollo propuesto. La norma técnica respectiva regulará lo dispuesto en este artículo (VENEZUELA, 2006, resaltado y subrayado nuestro).

Así mismo, la Ley de Gestion de la Diversidad Biológica ${ }^{5}$ establece en su artículo 6 que en la formulación y ejecución de la política en materia de gestión de la diversidad biológica, deberá incorporarse la prevención de los daños a sus componentes y su entorno, como elemento prioritario de conservación de estos bienes jurídicos ambientales en todos los planes, programas, proyectos, actividades o cualquier otra acción o medida emprendida por cualquier persona natural o jurídica, pública o privada, nacional o extranjera.

Del mismo modo, el Decreto 1.257 publicado en la Gaceta Oficial 35.946 del 25 de abril de 1986 mediante el cual se dictan las Normas sobre Evaluación Ambiental de Actividades Susceptibles de Degradar el Ambiente establece igualmente el requerimiento del necesario estudio de Impacto Ambiental. En este sentido el artículo 3 de dicho decreto establece que el estudio de impacto ambiental consiste:

[...] en un estudio orientado a predecir y evaluar los efectos del desarrollo de una actividad sobre los componentes del ambiente natural y social y proponer las correspondientes medidas preventivas, mitigantes y correctivas a los fines verificar el cumplimiento de las disposiciones ambientales contenidas en la normativa legal vigente en el país y determinar los parámetros ambientales que conforme a la misma deben establecerse para cada proyecto o programa.

Igualmente, el artículo 6 de dicho decreto prevé que el Ministerio del Ambiente y de los Recursos Naturales Renovables requerirá la presentación de un Estudio de Impacto Ambiental para los programas y proyectos relativos a las siguientes actividades:

5 Gaceta Oficial n. 39.070 de fecha 1 de diciembre 2008 
Minería .... Explotación o procesamiento de bauxita...

1-Explotación o procesamiento de minerales o piedras preciosas...

2-Forestal: aprovechamiento o explotaciones forestales de bosques no sujetos a Planes de Ordenación y Manejo Forestal, con una superficie efectiva que supere las $50 \mathrm{Ha}$ y pendientes mayores al $15 \%$.

Aprovechamiento o explotaciones forestales de bosques no sujetos a Planes de Ordenación y Manejo Forestal, con una superficie mayor de 500 ha. Y una intensidad de explotación mayor o igual a 5 árboles por hectáreas.

Así las cosas, el referido decreto, muy importante en Venezuela, exige de igual manera el Estudio de Impacto Ambiental para las actividades mineras y ello es ratificado en el procedimiento para actividades mineras e hidrocarburos previsto en los artículos 15 y siguientes, donde se requieren además aprobaciones para la ocupación del territorio (art. 15), autorizaciones para la afectación de recursos naturales renovables (artículo 17), así como la autorización de afectación de recursos naturales renovables para la fase de perforación exploratoria. Igualmente, dicha normativa requiere estudios de impacto ambiental para afectación de recursos naturales renovables para el desarrollo de explotación temprana y la instalación de planes pilotos. ${ }^{6}$

De igual manera en los casos de explotaciones mineras los beneficiarios de contratos y concesiones deben tramitar las correspondientes autorizaciones para la afectación de los recursos naturales renovables, así como deben presentar Estudio de Impacto Ambiental que debe ser elaborado como instrumento de incorporación de las consideraciones ambientales en el Estudio de Factibilidad Técnico Económica y el correspondiente programa de explotación minero (artículo 20 del referido Decreto 1.257).

Para la Corte Interamericana de Derechos Humanos (Corte IDH), en su Opinión Consultiva 23 del año 2017 (en adelante "OC23") se establece que el principio de prevención se refiere a las medidas que deben tomar los Estados para prevenir el daño significativo al medio ambiente, dentro o fuera de su territorio, siendo este "cualquier daño al medio ambiente que pueda conllevar una violación de los derechos a la vida o a la integridad personal".

Igualmente, establece la OC23-17 que las medidas que deben adoptar los

6 Consúltese: Blanco-Uribe Quintero, Alberto: La Regulación Jurídica de la Evaluación Ambiental en Venezuela. Publicado por: Aveda.org.ve/files/biblioteca/blancouribe/013.pdf. Ponencia presentada para el Seminario Internacional en Derecho Ambiental "La regulación del Impacto Ambiental en la Región Puebla, Panamá" México, Universidad de Quintana Roo, febrero de 2002. 
Estados para cumplir con la obligación de prevención, se encuentran los deberes de: i) regular; ii) supervisar y fiscalizar; iii) requerir y aprobar estudios de impacto ambiental; iv) establecer un plan de contingencia; y v) mitigar en casos de ocurrencia de daño ambiental.

\subsubsection{Principio de Cooperación}

Entre los Estados: derivado de la Convención de Río y OC 23. La obligación de cooperación es una obligación entre Estados.

Se encuentra contemplada en la Declaración de Rio:

PRINCIPIO 7: Los Estados deberán cooperar con espíritu de solidaridad mundial para conservar, proteger y restablecer la salud y la integridad del ecosistema de la Tierra. En vista de que han contribuido en distinta medida a la degradación del medio ambiente mundial, los Estados tienen responsabilidades comunes pero diferenciadas. Los países desarrollados reconocen la responsabilidad que les cabe en la búsqueda internacional del desarrollo sostenible, en vista de las presiones que sus sociedades ejercen en el medio ambiente mundial y de las tecnologías y los recursos financieros de que disponen.

Según la OC23 de la Corte Interamericana de DDHH, párrafo 182, “en el caso concreto de actividades, proyectos o incidentes que puedan generar dańos ambientales significativos transfronterizos, el Estado o los Estados potencialmente afectados requieren de la cooperación del Estado de origen y viceversa, a efectos de adoptar las medidas de prevención y mitigación que fueran necesarias para garantizar los derechos humanos de las personas bajo su jurisdicción. Por otro lado, el cumplimiento por parte del Estado de origen de su obligación de cooperación es un elemento importante en la evaluación de su obligación de respetar y garantizar los derechos humanos de las personas fuera de su territorio que pudiera verse afectadas por actividades realizadas dentro de este"?

Según la OC23 de la Corte Interamericana de DDHH, párrafo 186, esta obligación contempla ciertos deberes específicos tales como i) el deber de notificación; ii) el deber de consultar y negociar con los Estados potencialmente afectados; y iii) la posibilidad de intercambio de información que se establece en múltiples instrumentos internacionales en materia ambiental.

7 https:/www.itlos.org/fileadmin/itlos/documents/cases/case_no_10/published/C10-O-3_dec_01.pdf. El Tribunal Internacional del Derecho del Mar establece en el párrafo 82 de su sentencia "Caso de la planta MOX (Irlanda Vs. Reino Unido). Orden de medidas provisionales del 3 de diciembre de 2001, que "se ha determinado que la obligación de cooperación proviene del derecho internacional general y constituye un principio fundamental en la prevención de la contaminación del ambiente marino. 
El deber de notificación conlleva la obligación de notificar a los Estados potencialmente afectados por posibles daños significativos al medio ambiente causados por actividades llevadas a cabo bajo su jurisdicción. El momento oportuno para notificar: "surge cuando el Estado de origen adquiere conocimiento o determina que una actividad realizada bajo su jurisdicción conlleva o podría conllevar posibles riesgos de daños transfronterizos significativos".

El deber de consultar y negociar con los Estados potencialmente afectados que puede ser relevante para el caso del Arco Minero es una forma de cooperación para prevenir o mitigar daños transfronterizos. La Corte Internacional de Justicia ha reconocido este deber en el Caso de las Plantas de Celulosa sobre el Rio Uruguay (Sentencia del 20 de abril de 2010, en sus párrafos 144 y 147), al indicar que mientras se esté llevando a cabo un mecanismo de cooperación entre los Estados para prevenir daños significativos al medio ambiente, el Estado de origen está obligado a no autorizar el proyecto $y$, con mayor motivo, a no ejecutarlo, pues de lo contrario no tendría sentido el mecanismo de cooperación y cualquier negociación entre las partes carecería de propósito.

\subsubsection{Principio de prudencia}

Se ha sostenido por la doctrina más calificada en Venezuela en Derecho Ambiental (MEIER, 2011) que la Prudencia conlleva a la precaución o a la prevención. Conlleva a la prevención porque el administrador ante lo frágil del medio ambiente debe ser prudente "Prudencia preventiva" y para ello tiene el instrumento del estudio de impacto ambiental. (Artículo 129 de la Constitución vigente en Venezuela "Todas las actividades susceptibles de generar daños a los ecosistemas deben ser previamente acompañadas de estudios de impacto ambiental y socio cultural").

Así mismo, la prudencia exige el rechazo del proyecto cuando sus efectos generan daños (daño previsible artículo 83 de la "LOA"), así como también, llama a la utilización de la mejor tecnología.

De igual manera, el principio de prudencia puede derivar de la Constitución en su artículo 129 el cual establece que los contratos que celebre la República con personas naturales o Jurídicas ya sean estas nacionales o extranjeras o en los permisos que se otorguen que involucren los recursos naturales, se debe considerar incluida una cláusula -así no haya sido expresamente estipulada o escrita de la obligación de conservar el equilibrio ecológico.

Así mismo, el principio de prudencia se puede derivar del artículo 47 de la "LOA": 
La Autoridad Nacional Ambiental, ante la presunción o inminencia de impactos negativos al ambiente, deberá prohibir o, según el caso, restringir total o parcialmente actividades en ejecución que involucren los ecosistemas, recursos naturales o la diversidad biológica, sin que ello genere derechos de indemnización.

Artículo 84: La evaluación de impacto ambiental está destinada a: 1. Predecir, analizar e interpretar los efectos ambientales potenciales de una propuesta en sus distintas fases.

2. Verificar el cumplimiento de las disposiciones ambientales.

3. Proponer las correspondientes medidas preventivas, mitigantes y correctivas a que hubiere lugar.

4. Verificar si las predicciones de los impactos ambientales son válidas y las medidas efectivas para contrarrestar los daños (VENEZUELA, 2006).

\subsubsection{Principio de Corrección por prioridad de la fuente de donde emanan actividades degradantes: LOA (art. 10.1)}

\subsubsection{Principio de Responsabilidad por Daño Ambiental}

La Ley Orgánica del Ambiente (LOA) establece la responsabilidad objetiva y medidas accesorias administrativas, En efecto el Artículo 4 establece:

La gestión del ambiente comprende:

$[\ldots]$

8. Responsabilidad en los daños ambientales: La responsabilidad del daño ambiental es objetiva y su reparación será por cuenta del responsable de la actividad o del infractor (VENEZUELA, 2006, subrayado nuestro).

Igualmente, según lo establecido en la LOA, la simple existencia del daño determina la responsabilidad en el agente dañino (art. 116). Responsabilidad objetiva: "La responsabilidad derivada de daños causados al ambiente es de carácter objetiva, la simple existencia del daño determina la responsabilidad en el agente dañino de haber sido el causante de ese daño, y por tal quien deberá indemnizar los dańos y perjuicios causados por su conducta. Queda exceptuada el de probar el nexo de causalidad entre la conducta ejercida y el daño causado, bastando la simple comprobación de la realización de la conducta lesiva” (VENEZUELA, 2006). 
Responsabilidad Penal por delitos ambientales, solo basta la comprobación de la violación, no siendo necesaria la demostración de la culpabilidad.

Artículo 131 Responsabilidad penal por delitos ambientales: La determinación de la responsabilidad penal en los delitos ambientales, es objetiva, para lo cual sólo basta la comprobación de la violación, no siendo necesario demostrar la culpabilidad.

Artículo 132 Responsabilidad de las personas jurídicas: Las personas jurídicas serán responsables por sus acciones y omisiones por delitos cometidos con ocasión de la contravención de normas o disposiciones contenidas en leyes, decretos órdenes, ordenanzas, resoluciones" y otros actos administrativos de carácter general o particular de obligatorio cumplimiento. Las personas jurídicas serán sancionadas de conformidad con lo previsto en el artículo 130 de esta Ley, en los casos en que el hecho punible haya sido cometido a causa del ejercicio de sus actividades o en su representación, o por orden suya y en su interés exclusivo o preferente (VENEZUELA, 2006).

Así mismo la "LOA" en su artículo 133 establece las medidas que una sentencia condenatoria puede tomar.

Por otra parte, en cuanto al ejercicio legal de la minería El artículo 44 del Decreto con Rango, Valor y Fuerza de Ley Orgánica que Reserva al Estado las Actividades de Exploración y Explotación del Oro y demás Minerales Estratégicos ${ }^{8}$ establece el delito de ejercicio ilegal de la minería, en los términos siguientes:

Artículo 44. Las personas naturales, así como los socios y directores de las personas jurídicas, bien sean de carácter público o privado, nacional o extranjero, que por sí o por interpuesta persona, promuevan, inciten y realicen las actividades primarias, conexas o auxiliares a las que se refiere este Decreto con Rango, Valor y Fuerza de Ley Orgánica, sin cumplir con las formalidades establecidas, serán penadas con prisión de seis (06) meses a seis (06) años (VENEZUELA, 2006).

Así mismo, el referido artículo establece una agravante en su último aparte, al señalar que "en el caso que las actividades señaladas en este Decreto con Rango, Valor y Fuerza de Ley "sean desarrolladas en parques nacionales", la pena aplicable será de prisión de cinco (05) a diez (10) años”.

8 G.O. n. 6.210 Extraordinario de fecha 30 de diciembre de 2015. 


\subsubsection{Otorgamiento de permisos o autorizaciones sin estudios de impacto ambiental}

El artículo 43 de la Ley Penal del Ambiente establece la responsabilidad penal en que puede incurrir el funcionario público que otorgue permisos o autorizaciones sin estudios de impacto ambiental, en los términos siguientes:

Artículo 43. El funcionario público o funcionaria pública que otorgue permisos o autorizaciones sin exigir, evaluar y aprobar el estudio de impacto ambiental y sociocultural u otras evaluaciones ambientales en las actividades para las cuales lo exigen las normas sobre la materia, será sancionado o sancionada con arresto de tres meses a un año. La sanción acarreará la inhabilitación para el ejercicio de funciones o empleos públicos hasta por dos ańos después de cumplida la pena principal (VENEZUELA, 2012).

\subsubsection{Principio de Represión: LOA (art. 108)}

En ejecución de la Ley Orgánica del Ambiente, "deberán dictarse las adecuadas normas penales y administrativas en garantía de los bienes jurídicos tutelados por la misma. Las sanciones pecuniarias correspondientes serán hasta de diez mil unidades tributarias (10.000UT); y hasta de diez años de prisión si consistieren en penas privativas de libertad debiéndose hacer la fijación de acuerdo con la mayor gravedad del hecho punible a las condiciones del mismo y a las circunstancias de su comisión, manteniendo la debida proporcionalidad y adecuación con el supuesto de hecho"”.

\subsubsection{Principio de Primacía del Interés Público Ambiental}

De acuerdo al artículo 4.7 de la "LOA" se prevé una limitación de los Derechos individuales que se conoce también como la primacía de los intereses colectivos. Sin embargo, ello no quiere decir según Meier que siempre y en todas las circunstancias se sacrifiquen otros intereses valores y bienes, sino que hay que ponderar los derechos bienes e intereses y procurar la búsqueda de equilibrio. ${ }^{10}$

9 En la Unión Europea se ha establecido el principio de contaminador pagador (relacionado a la prevención y reparación.) Desarrollo normativo en Directiva 2004/35 Del Parlamento Europeo y del Consejo, 21 de abril de 2004. Sobre responsabilidad medioambiental en relación con la prevención y reparación de daños medioambientales. https://eur-lex.europa.eu/LexUriServ/LexUriServ.do?uri=OJ:L:2004:143:0056:0075:es:PDF

10 Consúltese en este sentido Meier Henrique: Categorías Fundamentales Op Cit pág. 74 quien señala que lo que es claro es que la tutela del ambiente no admite discusión en cuanto a proyectos y actividades que causen daños 


\subsubsection{Obligación de procedimiento para garantizar los} derechos a la vida y a la integridad personal en el contexto de la protección del medio ambiente. Consulta previa a los indígenas para garantizar el derecho de acceso a la información y participación pública

Se establece en la Constitución de la República Bolivariana de Venezuela en el artículo 119 (CRBV) la facultad del Ejecutivo Nacional, con la participación de los referidos pueblos y comunidades indígenas, de demarcar sus tierras y garantizar la propiedad colectiva. Se establece así mismo, que el aprovechamiento de los recursos naturales en los hábitats indígenas por parte del Estado se realizará sin lesionar la integridad cultural, social y económica de los mismos y está sujeta a la previa información y consulta a dichas comunidades (art. 120 CRBV).

\section{El Decreto del Arco minero y la violación de los principios rectores constitucionales y legales en Derecho Ambiental}

La segunda parte del presente trabajo tiene como objetivo patentizar como mediante la aprobación del Decreto del Arco Minero del Orinoco (en lo adelante AMO) y sus actos de ejecución se han violado diversos principios rectores constitucionales en materia ambiental así como las normas legales, tales como los principios referidos en la primera parte de este trabajo: el principio de desarrollo sustentable, el principio de precaución, prevención, la ausencia de estudios de impacto ambiental y la no realización de consultas previas y obligatorias de comunidades indígenas, la afectación de Parques Nacionales, la afectación de derechos humanos (derecho a la asociación, derecho a huelga, derecho a un ambiente sano y libre de contaminación, derecho a la vida y a la integridad personal, derecho a la propiedad, derecho a la consulta previa y del derecho al consentimiento libre, previo e informado) y la militarización de territorios indígenas.

\subsection{Contexto, ubicación y extensión del Arco Minero}

Se busca explotar y comercializar los minerales: Bauxita, Coltán, Diamantes, Oro, Hierro, Cobre, Caolín y Dolomita.

irreversibles al ambiente artículo 83 de la "LOA"; por ejemplo, aprobar un proyecto de urbanización en una zona declarada como parque nacional o una industria siderúrgica en una zona declarada como reserva de la biosfera. De igual manera se sostiene la no posibilidad de alegar la teoría de derechos adquiridos cuando se trata de proteger el medio ambiente y los recursos naturales. 


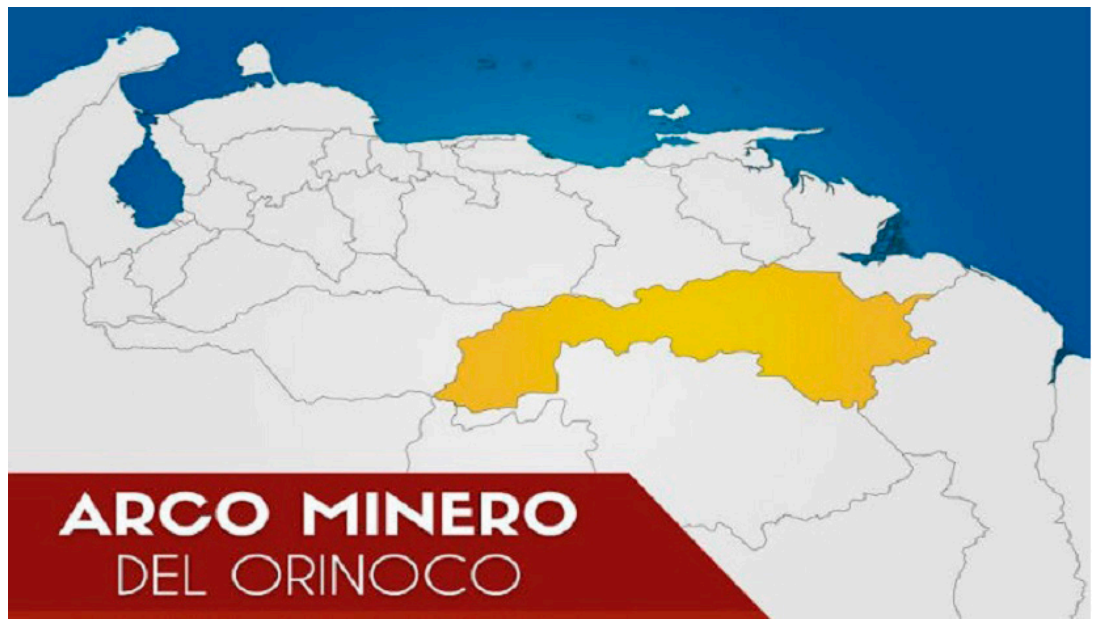

Figura 1 Superficie $111.843,70 \mathrm{~km}^{2}$ à $12,2 \%$ del territorio nacional.

\subsection{La industria extractiva como objetivo estratégico nacional}

Se establece en el Plan de la Patria 2013-2019 publicado en la Gaceta Oficial n.6-118 Extraordinario de fecha 4 de diciembre de 2013 el Gran Objetivo Histórico n. 3:

III. Convertir a Venezuela en un país potencia en lo social, lo económico y lo político dentro de la Gran Potencia Naciente de América Latina y el Caribe, que garanticen la conformación de una zona de paz en Nuestra América.

Así mismo se prevé como objetivo nacional:

3.1. Consolidar el papel de Venezuela como Potencia Energética Mundial.

Objetivos Estratégicos y Generales

3.1.15.3. Duplicar las reservas minerales de bauxita, hierro, coltán (niobio y tantalita), níquel, roca fosfórica, feldespato y carbón, con la certificación de los yacimientos ubicados en el Escudo de Guayana, Cordillera de los Andes, Sistema Montañoso del Caribe y la Sierra de Perijá.

3.1.16.4. Conformar empresas mixtas para la explotación y procesamiento de bauxita, hierro, coltán (niobio y tantalita), níquel, 
roca fosfórica, feldespato y carbón;

en las cuales la República tenga el control de sus decisiones y mantenga una participación mayoritaria.

\section{Objetivo Nacional}

3.2. Desarrollar el poderío económico en base al aprovechamiento óptimo de las potencialidades que ofrecen nuestros recursos para la generación de la máxima felicidad de nuestro pueblo, así como de las bases materiales para la construcción de nuestro socialismo bolivariano.

Objetivos Estratégicos y Generales

3.2.1.5. Desarrollar el aprovechamiento soberano tanto en la extracción como en el procesamiento de los minerales no metálicos; técnicas de maximización del rendimiento y cuidado ambiental, en especial de las cadenas de cemento y agregados de construcción, vidrio e insumos productivos especiales (feldespato, caolín, cal, cal siderúrgica, yeso, caliza, sílice, soda ash, entre otros) y nuevos desarrollos como el coltán (VENEZUELA, 2013).

Así se prevé la industria extractiva como objetivo estratégico nacional y se establece y prioriza la industria extractiva de minerales previéndose la constitución de empresas mixtas (INFANTE; GONZALES, 2018).

El gobierno venezolano en virtud de la caída y reducción de los precios del petróleo en los últimos años decidió decretar el Arco Minero del Orinoco a los fines de atraer inversiones y procurar un crecimiento económico a través de un proyecto de megaminería fundamentado en el plan de la patria 2013-2019. De tal manera que el gobierno venezolano apunta, así como lo ha realizado, con el petróleo, ahora con la minería, a una industria extractiva para alimentar el crecimiento económico.

Ahora bien, dicho desarrollo debe realizarse sin destrucción ambiental, efectuando un desarrollo ecológicamente sustentable y sostenible, preservando los bienes ambientales que conforman la base material del proceso: suelos, capa vegetal, aguas bosques, especies vivas, y aplicando los principios rectores previstos en la Constitución y las leyes. En efecto, en este sentido por ejemplo el artículo 50 de la LOA prevé que "El Aprovechamiento de los recursos naturales y de la diversidad biológica debe hacerse de manera que garantice su sustentabilidad" (VENEZUELA, 2006). 
Así el propio Plan de la Patria en su objetivo Estratégico y General establece:

3.3.1 Desarrollar la capacidad de producción del país en línea con las inmensas reservas de hidrocarburos, bajo el principio de la explotación racional y la política de conservación del recurso natural agotable y no renovable.

5.4.1 Continuar la lucha por la preservación, el respeto y el fortalecimiento del régimen climático conformado por la Convención Marco de Naciones Unidas para el Cambio Climático y su Protocolo de Kyoto. De tal manera que de acuerdo a lo establecido en el propio Plan de la Patria la explotación debe ser racional y teniendo en cuenta la conservación de los recursos naturales agotables y no renovables, así como con respecto a la Convenciones del cambio climático y el Protocolo de Kyoto (VENEZUELA, 2013, Subrayado nuestro).

\subsection{En el marco del Estado de Excepción se crea la "Zona de Desarrollo Estratégico Nacional Arco Minero del Orinoco" (Decreto 2.248, Gaceta Oficial n. 40.855 de fecha 24 de febrero 2016) Vulneración del artículo 150 de la Constitución venezolana vigente}

Se emite por el presidente de la República el Decreto de "Estado de Excepción y de Emergencia Económica" (Decreto 2.323 G.O.E. n. 6.227 de fecha 13 de mayo 2016).

que permite al Ejecutivo Nacional aprobar contratos de interés público para [...] el aprovechamiento de recursos estratégicos para el desarrollo económico del país sin sometimiento a autorizaciones o aprobaciones de otros Poderes Públicos, vulnerando así el artículo 150 CRBV. Asi el Presidente de la República a través de una figura irregular del establecimiento de un continuo "estado de excepción" Emite el decreto de arco minero que establece en su artículo 2 que la aprobación y suscripción por parte del Ejecutivo Nacional de contratos de interés público para [...] el aprovechamiento de recursos estratégicos para el desarrollo económico del país se realizará sin sometimiento a autorizaciones o aprobaciones de otros Poderes Públicos (VENEZUELA, 2016). 
Dicha previsión pretende que el Decreto del Arco Minero no sea aprobado por la Asamblea Nacional, cuando implica grandes contratos de interés públicos nacional, de enorme magnitud económica, vulnera lo establecido en el artículo 150 de la CRBV que establece que la celebración de contratos de interés público nacional requieren la aprobación de la Asamblea Nacional.

Así las cosas, el Ejecutivo Nacional utiliza la figura de estado de excepción para eludir el control político efectuado por los representantes del pueblo en la Asamblea Nacional.

El Decreto del Arco Minero (AMO) fue desconocido y desaprobado mediante acuerdo emitido por la Asamblea Nacional el 14 de junio de 2016, rechazando el decreto de creación del Arco Minero del Orinoco que dejaría sin efecto los contratos de creación de las empresas mixtas creadas para su exploración y explotación.

\subsection{Acuerdo de la Asamblea Nacional de fecha 14 de junio de 2016 Rechazando el Decreto de Creación de Zona Estratégica Arco Minero del Orinoco (AMO). El cual es desconocido por el Ejecutivo Nacional posteriormente}

El Decreto del AMO y las firmas de convenios y contratos con empresas ha vulnerado la Constitución de la República Bolivariana de Venezuela (art. 150 y 187 numeral 9) ya que fueron dictados y realizados de manera inconsulta y sin la aprobación, al tratarse de contratos de interés nacional y de alta envergadura, por la Asamblea Nacional.

Debemos seńalar que el Decreto del Arco Minero fue impugnado y demandada su nulidad ${ }^{11}$ por una plataforma creada por distintas asociaciones y ONG las cuales demandaron su nulidad por ante la Sala Político Administrativa del Tribunal Supremo de Justicia con solicitud de medida cautelar. En fecha de 21 de junio de 2016 dicha demanda fue admitida y el 27 de octubre del mismo año fue declarada improcedente la medida cautelar de suspensión de efectos de dicho decreto.

Según el Informe de la Comisión Mixta de la Asamblea Nacional de creación de la zona de Desarrollo Estratégico Nacional Arco Minero del Orinoco (AMO), del año 2017, la exploración y explotación del AMO coloca en riesgo las reservas de agua dulce de la zona y los bosques tropicales, además de la energía sustentable representada en los bloques de represas estratégicas de la cuenca del rio Caroní que surten de energía hidroeléctrica a más del 65\% del país.

11 Introducen recurso al TSJ para anular Decreto del Arco Minero http://laiguana.tv/articulos/28829-arco-minero-tsj 
Igualmente, la Asamblea Nacional se pronunció mediante Acuerdo suscrito en fecha 14 de junio de 2016 negando la autorización constitucional al Ejecutivo Nacional para el proyecto del Arco Minero del Orinoco (AMO) con el objetivo de proteger las últimas reservas de agua dulce, no contaminadas del país, la riqueza en biodiversidad contenida en la Reserva Forestal Imataca, la Reserva Forestal El Caura, La Paragua, las zonas protectoras, la Cuenca del Río Caroní, los Tepuyes, el hábitat de los pueblos indígenas, y demás Áreas Bajo Régimen de Administración Especial, Áreas Protegidas o de Especial Importancia Ecológica. Así mismo, en dicho acuerdo parlamentario se proclamó que se mantienen en vigencia Constitucional y legal, las Areas bajo Régimen de Administración Especial, áreas protegidas o de especial importancia ecológica, de todo el país, en particular las ubicadas en los estados Bolivar, Amazonas, Delta Amacuro conocidas como reservas de Imataca, el Caura, La Paragua, Monumento Natural Cerro Guanay y demás Tepuyes, la zona protectora del rio Orinoco, la cuenca estratégica del Caroní u otras que poseen protección constitucional y legal”.

Sin embargo, dado el conflicto de poderes públicos en Venezuela este acuerdo relevante de la Asamblea Nacional es desconocido por las autoridades del gobierno nacional.

\subsection{Impacto Negativo de Proyecto de Exploración y Explotación del AMO y Violación de los Principios Rectores en Materia Ambiental}

\subsubsection{Ausencia o falta de estudio de impacto ambiental Art. $129 C R B V$}

Falta de Estudio de Impacto Ambiental (Art. 129 CRBV y Art. 55 Ley Orgánica de Pueblos y Comunidades Indígenas LOPCI).

El Decreto de exploración y explotación del AMO viola los principios rectores en material ambiental como lo constituye el principio de prevención al no haber efectuado debidamente el Estudio de Impacto Ambiental. En efecto la Constitución venezolana vigente establece en el art. 129:

Artículo 129 CRBV: Todas las actividades susceptibles de generar dańos a los ecosistemas deben ser previamente acompañadas de estudios de impacto ambiental y socio cultural (VENEZUELA, 1999).

De igual manera la Ley Orgánica los Pueblos y Comunidades Indígenas establece en su art. 55: 
Artículo 55 LOPCI: Todo proyecto de desarrollo público, privado o mixto en hábitat y tierras indígenas, debe contar, previo a su aprobación y ejecución por el órgano competente, con un Estudio de Impacto Ambiental y sociocultural. Los pueblos y comunidades indígenas serán consultados en la etapa de elaboración y evaluación de los estudios de impacto ambiental y sociocultural, pudiendo objetarlos cuando éstos afecten la integridad sociocultural y ambiental. Las observaciones serán incorporadas en la reformulación del estudio, previo al análisis respectivo. Para garantizar este derecho, los pueblos y comunidades indígenas podrán solicitar asistencia técnica y jurídica al ente rector de la política indígena del país, a las organizaciones indígenas o a cualquier otro órgano o ente del estado o privado con competencia en la materia (Subrayado nuestro).

Dichas violaciones a los referidos artículos, además de la vulneración a la "LOA", (artículos 84 y 85) constituyen una vulneración a los principios rectores en materia ambiental previstos en normas constitucionales y legales, que forman parte del Derecho Internacional y del Derecho interno venezolano como lo constituyen los principios de precaución, prevención y prudencia establecidos tanto en la Constitución venezolana vigente como en el desarrollo legislativo venezolano. En efecto, la ausencia o falta de estudio de impacto ambiental ha sido reconocida incluso expresamente por los representantes del actual gobierno de Venezuela presidido por Nicolás Maduro por ante la Comisión Interamericana de Derechos Humanos (CDIH) durante el período de sesiones n. 159 en Ciudad de Panamá en fecha 2-12-2016. Así las cosas, Larry Devoe, Jefe de la delegación oficial venezolana, reconoció que el Ejecutivo Nacional tendrá en su momento los estudios sobre el impacto ambiental y sociocultural de la zonas que cubren el AMO "Esta previsto realizar los estudios de impacto ambiental como lo exigen la constitución y la ley antes de iniciar estas operaciones" reveló Devoe al referirse al área donde se desarrollara el arco minero ${ }^{12}$.

\subsubsection{Violación al Principio de Precaución}

El Estado no ha cumplido con el principio de precaución, ante los posibles daños graves e irreversibles al ambiente, no ha optado por escuchar las advertencias de diferentes grupos de la sociedad civil, incluyendo expertos, ni ha convocado a los diferentes sectores para conocer sus opiniones sobre los riesgos y daños posibles

12 El estímulo, noticias que te mueven 6-12-2016 http://elestimulo.com/blog/gobierno-revela-que-no-hizo-estudio-ambiental-del-arco-minero-del-orinoco/ 
al ambiente. Tampoco ha elaborado, ni ha ofrecido estudios que demuestren que se impedirá la degradación ambiental. La normativa internacional ${ }^{13}$ (Convenio de Rio), la constitución venezolana (artículo 129 CRBV), la "LOA" (artículo 4.3) y el Decreto 1.257 (artículos 3.1 y 15 y ss) obligan, en virtud del principio de Precaución, en caso de duda respecto al desarrollo de una actividad y siempre que haya riesgo que deben evitarse o no autorizarse dichas actividades o proyectos. Por consiguiente, es al Estado venezolano al que corresponde demostrar plenamente con los Estudios de Impacto Ambiental ante la opinión pública que el AMO no ocasionará daños.

\subsubsection{Violación al Principio de Prevención}

Como se ha destacado en el presente trabajo no existen estudios, ni información pública calificada y realizada con estándares internacionales que garanticen que el Estado venezolano tiene la certeza empírica, científica y académica de los impactos en la implementación del proyecto de mega minería del AMO como tampoco se han establecido de manera clara las medidas a implementar para evitarlos y en su caso mitigarlos. El Estado venezolano debe prevenir con estudios rigurosos, técnicos imparciales e independiente, las consecuencias del AMO en cumplimiento de su obligación de proteger el ambiente, la biodiversidad, la atmósfera y propender a un ambiente sano y aun desarrollo ecológicamente sustentable.

\subsubsection{El Decreto del Arco Minero del Orinoco hace prevalecer los intereses del Estado sobre los intereses particulares y menoscaba el derecho de reunión asociación pacífica}

El artículo $25^{14}$ del Decreto de Creación de la Zona Estratégica de Desarrollo Integral "Arco Minero del Orinoco" elimina principios de universalidad y progresividad en derechos humanos, así como contenidos inherentes al derecho a la libertad y asociación pacífica. El decreto establece que los intereses de Estado en el proyecto es el de maximizar la producción minera en la zona, encontrándose por encima de los derechos de las personas. En efecto, el artículo 25 establece: "Ningún interés particular, gremial, sindical, de asociaciones o grupos, o sus normativas, prevalecerá sobre el interés general en el cumplimiento del objetivo contenido en el presente decreto".

13 Carta Mundial de la Naturaleza, Principio 11(b), G.A. Res. 37/7, 28 de octubre de 1982; Convenio sobre la Diversidad Biológica, Preámbulo, "760 U.N.T.S. 793 I.L.M. 818, 5 de junio de 1992; Programa 21, parr. 13.40(b) (iv, U.N.Doc. A/ CONF.15 /26/ REV (VOL.II) (1995), Convención Marco de Cambio Climático, art. 3, 31 I.L.M. 849 (1992)

14 Artículo 25 del Decreto n. 2.248 mediante el cual se crea la Zona de Desarrollo Estratégico Nacional "Arco Minero del Orinoco": Ningún interés particular, gremial, sindical, de asociaciones o grupos, o sus normativas, prevalecerá sobre el interés general en el cumplimiento del objetivo contenido en el presente decreto. 
Por otra parte, el mismo Decreto 25 obstaculiza inconstitucionalmente el derecho a la manifestación pacífica y el derecho a huelga al establecer: "los sujetos que ejecuten o promuevan actuaciones materiales tendentes a la obstaculización de las operaciones totales o parciales de las actividades productivas serán sancionados conforme al ordenamiento jurídico aplicable"

Seguidamente el decreto establece, de manera discrecional, una política de seguridad que puede ocasionar graves violaciones de derechos humanos: "Los organismos de seguridad de Estado llevarán a cabo las acciones inmediatas necesarias para salvaguardar el normal desenvolvimiento de las actividades".

Estas disposiciones son violatorias de los artículos 53, 68 y 97 de la Constitución venezolana, es contrario a lo previsto en el Pacto Internacional de Derechos Civiles y Políticos; así como al convenio 87 de la Organización Internacional del Trabajo (OIT) relativo a la Libertad Sindical.

\subsubsection{Aceleración de deforestación en Venezuela}

Aceleración de deforestación en Venezuela, al contrario del resto de los países de la Pan Amazonia

En términos regionales, se verifica una tendencia a la disminución en la deforestación, la cual tiene un correlativo claro a nivel de Brasil, Bolivia, Ecuador. En algunos países hay ciertas variaciones a ese patrón, con repuntes en períodos intermedios o evidencias de estabilización (Colombia, Perú, Suriname, Guyane Française y Guyana). El único país que muestra una tendencia opuesta es Venezuela, con evidencias de aceleración en la tasa de pérdida del bosque, $y$ en otros se verifica una tendencia al incremento en caso que el ritmo anual en el período 2010-2013 se mantenga (Guyane Française, Suriname y Venezuela)." [...] "La minería en Colombia, las Guayanas y Venezuela, así como la explotación de hidrocarburos en Ecuador, son importantes fuentes de deforestación, principalmente por el acceso facilitado por la construcción de caminos asociados a esas actividades productivas. Es previsible que la deforestación relativa a estas actividades vaya en aumento en los próximos años." (Deforestación en la Amazonía (1970-2013) RAISG Red Amazónica de Información Socioambiental Georreferenciada. p. $6,7,10{ }^{15}$

15 https://www.amazoniasocioambiental.org/es/publicacion/amazonia-2017-areas-protegidas-y-territorios-indigenas/ 
Juan Carlos Sanchez integrante del grupo Intergubernamental de Expertos sobre el cambio climático ha señalado que "uno de los daños ambientales que conllevaría el Decreto del Arco Minero seria la deforestación masiva necesaria para las excavaciones. Esto incidiría en el cambio climático, pues "La deforestación suprime el proceso de fotosíntesis que absorbe el CO” de la atmósfera, y a la vez emite CO2" que es el principal gas de efecto invernadero".

De igual manera Ana Eliza Osorio ex Ministra del Ambiente (2000-2005) ha señalado:

[...] que esto puede llevar a un proceso de desertificación al sur del país. Después de todo la capa vegetal de la zona no es recuperable. Lo que va a dejar abajo es caliza. Ósea, que ahí no va a crecer nada más. Los cuerpos acuáticos del Arco Minero también peligran. Afirma Osorio que el megaproyecto minero no se trata solamente de excavación, de deforestación, de arrasar con la superficie de todo lo que es la capa vegetal del suelo, que por cierto en Guayana es bastante frágil, sino que esta tierra que se moviliza se lava o se lixivia con cianuro. Y el cianuro, como sabemos, es un elemento totalmente toxico. Esas aguas lixiviadas, esa mezcla de agua con cianuro, teóricamente se van a colocar en unas lagunas que están impermeabilizadas para contenerlas. Pero ya ha habido experiencias, una no tan lejana en Argentina, donde la ruptura de una de esas lagunas comprometió ocho ríos. Entonces imagínate que aquí haya una ruptura o una percolación de este líquido hacia el rio Orinoco, hacia el rio Caroní, hacia el rio Cuchivero, hacia el rio Caura, que son la reserva de agua de nuestro país. Setenta por ciento de nuestras reservas de agua están en el del Orinoco (EGAÑA, 2016).

\subsubsection{El decreto del Arco Minero afecta y comprende áreas bajo régimen de administración especial y parques nacionales}

El decreto 2.248 comprende dentro de su extensión áreas de administración especial (ABRAES) las cuales están sometidas a un régimen de administración especial conforme a leyes y reglamentos particulares. Dentro de estas zonas conforme al artículo 15 de la Ley Orgánica de Ordenación de Territorio ${ }^{16}$ se encuentran los parques nacionales, zonas protectoras, reservas forestales, reserva de fauna silvestre y monumentos naturales entre otros.

$\overline{16 \text { Gaceta Oficial n. } 3.238}$ extraordinario de fecha 11 de agosto 1983. 
Dicha región del Arco Minero del Orinoco destinada para el desarrollo minero violando así la Ley Orgánica de Ordenación de Territorio y la normativa de áreas bajo régimen de administración especial (ABRAES) comprende, a su vez, siete monumentos naturales y cinco parques nacionales. Entre esos Parques Nacionales se encuentra el Parque Nacional Canaima, declarado Patrimonio Mundial por la UNESCO y que abarca una totalidad de 30.000 kilómetros cuadrados.

Según el Instituto Nacional de Parques (INPARQUES) los Parques Nacionales son "áreas y territorios que albergan ecosistemas que deben protegerse de la alteración por la explotación o la ocupación humana en Venezuela [...]"(VENEZUELA, 1983). Así mismo, se detalla que en tales áreas se permite la realización de actividades recreacionales, educativas y turísticas, así como de investigación científica, más no de minería.

Igualmente, la mencionada área incluye la Reserva Forestal de Imataca (3.800.000 hectáreas); las reservas de La Paragua y El Caura (5.134.000 hectáreas combinadas); el Monumento Natural Cerro Guanay; más el río Caroní (que abarca 96.000 kilómetros cuadrados). Según INPARQUES, los monumentos naturales de Venezuela son "áreas de superficie limitada, que, por sus peculiaridades naturales, continentales o marinas, merecen protección y perpetuidad en su estado original. Se les considera de interés nacional y suelen presentar por lo menos una característica sobresaliente, tales como accidentes geográficos, belleza o rareza excepcionales"(VENEZUELA, 2018). Según la organización Global Forest Watch (GLOBAL FOREST WATCH, 2018), al menos cinco áreas protegidas en Venezuela ya están siendo deforestadas por las actividades mineras ilegales. Cómo se mencionó anteriormente, el AMO incluye siete monumentos naturales y cinco parques nacionales sobre los cuales actualmente se realizan actividades de exploración y explotación minera por parte del Estado.

\subsubsection{Violación del Derecho a la consulta previa, libre e informada de las comunidades indigenas que babitan la zona}

La constitución vigente venezolana prevé que el aprovechamiento de los recursos naturales en los hábitats indígenas por parte del Estado se hará sin lesionar la integridad cultural, social y económica de los mismos. Igualmente se prevé en el artículo 120 de la Constitución que dicho aprovechamiento de los recursos naturales está sujeto a la previa información y consulta de las comunidades indígenas respectivas.

El grupo de expertos de comité de Derechos Humanos del alto Comisionado 
de las Naciones Unidas para los Derechos Humanos ha señalado en el Cuarto informe periódico de Venezuela sobre la aplicación del Pacto Internacional de Derechos Civiles y Políticos celebradas los días 29 y 30 de junio de 2015, recomendó al Estado venezolano "adoptar las medidas necesarias a fin de: a) Garantizar la celebración de las consultas previas necesarias con los pueblos indígenas a fin de obtener su consentimiento libre, previo e informado antes de adoptar y aplicar cualquier medida que pueda incidir sustancialmente en su modo de vida y su cultura, en particular en relación con proyectos que puedan tener un impacto sobre sus tierras o territorios y otros recursos, tales como proyectos de explotación y/o exploración de recursos naturales.

\subsubsection{Violación del Art. 55 Ley Orgánica de Pueblos y Comunidades Indigenas (LOPCI)}

Falta de consulta previa a las comunidades indígenas que habitan la zona (Art. 55 LOPCI)

El Decreto del Arco Minero (AMO) fue dictado sin el debido cumplimiento conforme el artículo 128 de la Constitución venezolana de un proceso de información que hubiese incluido la información, consulta y participación ciudadana. En efecto, de conformidad con el artículo 128 de la Constitución venezolana la política de ordenación del territorio debe realizarse de acuerdo con las premisas del desarrollo sustentable e incluyendo un proceso de consulta y participación ciudadana el cual se incumplió en este sentido el artículo 41 de la "LOA" establece que los pueblos indígenas y comunidades locales tienen el derecho y el deber de participar en la formulación, aplicación evaluación y control de los planes de desarrollo nacional regional y local susceptibles de afectarles directamente en sus vidas valores y creencias y en el uso de las tierras y hábitat que ancestralmente ocupan y utilizan colectivamente. Contrariamente a lo señalado por la Constitución y por el citado artículo 41 de la "LOA" el Decreto AMO se aprobó unilateralmente por el Ejecutivo Nacional sin que existiera un proceso de consulta ni de participación ciudadana, ni de participación de los pueblos indígenas, ${ }^{17}$ siendo un proyecto de gran escala de megaminería, que abarca el 12,2\% del territorio de Venezuela, afectando varios estados: Amazonas, Bolívar y Delta Amacuro con una superficie de $111.843 .70 \mathrm{~km}^{2}$, ubicado en el Estado Bolívar y se extiende desde el Estado Amazonas hasta el Estado Delta Amacuro y a la presente fecha es muy difícil por no decir imposible tener información

17 Provea, GTAI, LabPaz: Situación del Derecho a la Consulta Previa en Venezuela http://laboratoriosdepaz.org/ wp-content/uploads/2016/08/Informe_CP.pdf 
detallada de sus exactas implicaciones, consecuencias e impactos. De igual manera se incumple el artículo 119 de la Constitución por que el Ejecutivo Nacional no ha concluido con la participación de los pueblos indígenas la demarcación de sus territorios garantizando el derecho a la propiedad colectiva de sus tierras.

La demostración de que no hubo consulta es que se publicó el Decreto del Arco Minero (AMO) y se aprobó en todas sus dimensiones, territorio, extensión y bloques de extracción y es posteriormente a ello que simplemente se ha conversado con una representación vocera de las comunidades y pueblos indígenas. ${ }^{18}$

De allí pues, al no haberse realizado el proceso de consulta previa a los pueblos indígenas, ni haber permitido su participación, en la formulación, evaluación y control de dicho decreto se viola la vigente Constitución venezolana y las leyes especiales dictadas en la materia.

\subsubsection{Se vulneran los derechos que tienen las comunidades indigenas sobre "las tierras que ancestral y tradicionalmente ocupan amenazando su bábitat" (Art. 119 CRBV y Art. 29 LOPCI)}

El artículo 119 de la constitución vigente venezolana establece:

Artículo 119 CRBV: El Estado reconocerá la existencia de los pueblos y comunidades indígenas, su organización social, política y económica, sus culturas, usos y costumbres, idiomas y religiones, así como su hábitat y derechos originarios sobre las tierras que ancestral y tradicionalmente ocupan y que son necesarias para desarrollar y garantizar sus formas de vida. Corresponderá al Ejecutivo Nacional, con la participación de los pueblos indígenas, demarcar y garantizar el derecho a la propiedad colectiva de sus tierras, las cuales serán inalienables, imprescriptibles, inembargables e intransferibles de acuerdo con lo establecido en esta Constitución y la ley.

Artículo 120 de la Constitución de la CRBV: El aprovechamiento de los recursos naturales en los hábitats indígenas de los mismos e igualmente, está sujeto a previa información y consulta a las comunidades indígenas respectivas. Los beneficios de este aprovechamiento por parte de los pueblos indígenas están sujetos a esta Constitución y a la ley.

Artículo 29 LOPCI: De las formas de Propiedad Colectiva: La

18 Informe de Provea presentado el 2 de diciembre de 2016 ante el Presidente de la Comisión Interamericana de los Derecho Humanos, consultado en original. 
propiedad colectiva del hábitat y tierras de los pueblos y comunidades indígenas podrá ser de uno o más pueblos y de una o más comunidades indígenas según las condiciones, características y exigencias de los mismos (VENEZUELA, 1999).

De allí pues se hace evidente la vulneración de los derechos de propiedad de las comunidades indígenas sobre las tierras que ancestral y tradicionalmente ocupan, lesionando su integridad cultural y su hábitat al imponer de manera inconsulta importantes desarrollos mineros en los territorios decretados por el $\mathrm{AMO}^{19}$.

\subsubsection{0 violación del Derecho de Participación Previsto en la Declaración de Rio sobre el medio ambiente y el Desarrollo de 1992, suscrita por Venezuela}

La Declaración de Rio sobre el Medio Ambiente y el desarrollo de 1992, suscrita por Venezuela, obliga al Estado venezolano a cumplir con los principios internacionales del derecho ambiental. Con la aprobación del Decreto AMO no se está cumpliendo con el Principio 10 que reza:

El mejor modo de tratar las cuestiones ambientales es con la participación de todos los ciudadanos interesados, en el nivel que corresponda. En el plano nacional, toda persona deberá tener acceso adecuado a la información sobre el medio ambiente de que dispongan las autoridades públicas, incluida la información sobre materiales y las actividades que encierran peligro en sus comunidades, así como la oportunidad de participar en los procesos de adopción de decisiones. Los Estados deberán facilitar y fomentar la sensibilización y la participación de la población poniendo la información a disposición de todos. Deberá proporcionarse acceso efectivo a los procedimientos judiciales y administrativos, entre estos el resarcimiento de daños y los recursos pertinentes ${ }^{20}$.

A su vez, "Los principios de información y acceso a la Justicia", que son pilares fundamentales para garantizar un ambiente sano, permitiendo que las personas conozcan la situación actual y futura frente a posibles intervenciones

19 Véase en este sentido el Informe reciente del 4 de julio de 2019 de la Alta Comisionada de las Naciones Unidas para los Derechos Humanos, Michel Bachelet sobre la situación de los Derechos Humanos en Venezuela, y en especial el n.63 en https://www.panaroma.com.ve/politicayeconomía/Este- es-el-demoledor-informe-de Bachelet-sobre-la crisis-en-Venezuela-20190704.htlm

20 Declaración de Rio sobre el Medio Ambiente y el Desarrollo. Conferencia de las naciones Unidas sobre el medio ambiente y el desarrollo. http://www.cedaf.org.do/eventos/forestal/Legislacion/Inst_internac/DECLARACION_ RIO.PDF 
de su espacio de vida, para que tomen medidas y sean parte de las decisiones que pueden afectarlos y que es extensivo tanto a comunidades indígenas, pobladores y ciudadano/as de un país se vulneró con la población sin información pública, sin consulta y sin posibilidad de participar en la toma de decisiones sobre el Decreto AMO.

\subsubsection{Militarización de zonas boscosas (Decreto 2.323 G.O.E. n. 6.227 de fecha 13 de mayo de 2016)}

Decreto 2.323. “Estado de Excepción y de Emergencia Económica” establece en su artículo 2 la militarización en zonas boscosas:

El Ejecutivo Nacional podrá [...] 15: Dictar medidas de protección de zonas boscosas para evitar la deforestación, la tala y la quema que contribuyen a la disminución de las precipitaciones, alteran los ciclos hidrológicos e impactan de forma negativa amenazando los ciclos agro productivos y cosechas, mermando los niveles de producción y afectando el acceso del pueblo venezolano a bienes y servicios, cuya vigilancia estará a cargo de la Fuerza

Armada Nacional Bolivariana (VENEZUELA, 2016).

\subsubsection{Proliferación de minería ilegal}

Existe presencia de una cantidad de mineros ilegales con la aquiescencia del Estado. El gobierno no hace por desalojar a los mineros ilegales, están destruyendo parte de los monumentos naturales y saqueando y destruyendo extensiones de tierra. Con la minería ilegal han llegado a estas zonas malandros, bandas civiles armadas, criminales, atracadores, prostitución, entre otros. ${ }^{21}$

\section{Conclusion}

Luego de haber esbozado en el presente trabajo los principios rectores constitucionales y legales en materia ambiental en contraste hemos presentado diversas violaciones por parte del Estado venezolano a dichos principios rectores y normas de protección de los recursos naturales: En efecto, con el dictado del Decreto del Arco Minero n. 2.248 dictado por el presidente de la República publicado en la Gaceta Oficial n. 40.855 de fecha 24 de febrero 2016, se violan los principios de precaución, prevención y prudencia al no haberse efectuado el

21 Consúltese informe de Provea. 53 presentado interpuesto ante el presidente de la Comisión Interamericana de Derechos Humanos en fecha 2 de diciembre 2016. 
debido Estudio de Impacto Ambiental como lo prevé la propia constitución en su artículo 129 así como la "LOA” y el Decreto n. 1.257. Así las cosas, no se han elaborado ni ofrecido estudios que demuestren que se impedirá la degradación del ambiente y los recursos naturales y no existen estudios, ni información pública calificada y efectuada- con estándares internacionales- que garanticen con certeza empírica y científica los impactos en la implementación del proyecto de megaminería del AMO.

Por otra parte, se ha verificado una violación del derecho a la consulta y al consentimiento libre, previo, informado y de buena fe de los pueblos y comunidades indígenas, así como tampoco se ha efectuado ni concluido la debida demarcación de los territorios indígenas. Así mismo se ha vulnerado el artículo 150 de la Constitución de Venezuela, al realizar las firmas de contratos de extracción minera de gran magnitud económica sin la autorización debida de la Asamblea Nacional como representante del pueblo venezolano e igualmente se ha realizado un abuso de la figura del Estado de Excepción "continuado", a los efectos de facultar al Ejecutivo Nacional para decretar el AMO y autorizar contratos de interés nacional que deberían necesaria imprescindiblemente requerir de la autorización de la Asamblea Nacional.

De allí pues, se hace necesario el trámite urgente de medidas cautelares y realizar un informe, así como permitir la visita a Venezuela de la Relatoría de Derechos Humanos de los Pueblos Indígenas de la Comisión Interamericana de los Derechos Humanos a los fines de constatar las diferentes situaciones planteadas y entrevistarse así mismo con todos los actores. De igual manera, es imprescindible se efectúen los estudios de Impacto Ambiental y Socio Cultural en estricto cumplimiento con los estándares internacionales e igualmente se efectúe la consulta libre, informada y de buena fe a los pueblos y comunidades indígenas de cualquier proyecto que los pueda afectar; y de igual manera acelerar la aprobación del proyecto del reglamento de consulta previa e informada que actualmente cursa por ante la Asamblea Nacional; y evitar cualquier expansión del AMO hacia el territorio Amazonas, hasta tanto no se garanticen el cumplimiento de las obligaciones constitucionales y legales.

\section{Referencias}

EGAÑA, Carlos. El Arco Minero del Orinoco: ambiente, rentismo y violencia al sur de Venezuela. 23 de agosto 2016. Disponible: http://historico.prodavinci. com/2016/08/23/actualidad/el-arco-minero-del-orinoco-ambiente-rentismo-yviolencia-al-sur-de-venezuela-por-carlos. 
ESPAÑA. Sentencia del Tribunal Constitucional Español 64/82, 11 de noviembre, 1982.

INFANTE, Alfredo, GONZALES, Wilfred. Una mirada estructural del megaproyecto Arco Minero del Orinoco. Revista SIC Fundación Centro Gumilla (1) Caracas junio 2018. Disponible:https://revistasic.gumilla.org/2018/unamirada-estructural-del-megaproyecto-arco-minero-del-orinoco-i/

GLOBAL FOREST WATCH. 2018.Disponible: 201https://www. globalforestwatch.org/dashboards/country/VEN/6? category=forest-change..

MEIER, Echeverría, Henrique. Categorías Fundamentales de Derecho Ambiental. Ediciones Homero. Caracas 2011.

MEIER, Echeverría, Henrique. El Derecho Ambientaly el Nuevo Milenio. Ediciones Homero, Caracas 2003.

ONU. Declaración de Rio sobre el Medio Ambiente y el Desarrollo. Conferencia de las naciones Unidas sobre el medio ambiente y el desarrollo. 1992.

http://www.cedaf.org.do/eventos/forestal/Legislacion/Inst_internac/ DECLARACION_RIO.PDF

VENEZUELA. La Ley Orgánica del Ambiente (LOA), 2006. Disponible: $<$ http://www.monografias.com/trabajos92/ley-del-ambiente-y-ley-mina/ley-delambiente-y-ley-mina.shtml\#delaplania>.

VENEZUELA. La Ley Penal del Ambiente. G.O. n. 39.913 de fecha 2 de mayo de 2012. Disponível em: <http://www.mp.gob.ve/LEYES/ley\%20penal\%20del\%20 ambiente/Ley\%20Penal\%20del\%20Ambiente.html>.

VENEZUELA. Del Decreto con Rango, Valor y Fuerza de Ley Orgánica que Reserva al Estado las Actividades de Exploración y Explotación del Oro y demás Minerales Estratégicos; G.O. n. 6.210 Extraordinario de fecha 30 de diciembre de 2015 .

VENEZUELA. El Plan de la Patria 2013-2019. GAZETA OFICIAL, 2013.

VENEZUELA. Provea, GTAI, LabPaz: Situación del Derecho a la Consulta Previa en Venezuela http://laboratoriosdepaz.org/wp-content/uploads/2016/08/ Informe_CP.pdf

VENEZUELA. INPARQUES, 2018. Disponible: http://www.inparques.gob.ve. 
VENEZUELA. Decreto 2.323 .G.O.E. n. 6.227 de fecha 13 de mayo de 2016. Militarización de zonas boscosas.

VILLEGAS MORENO, Jose Luis. Derecho Administrativo Ambiental. Lebrería y Galeria sin Limite, San Cristobal, 2009. 